\title{
GROUP VELOCITIES OF SURFACE WAVES FROM NEAR EARTHQUAKES AROUND JAPAN
}

\author{
Tamotsu Furuzawa \\ Disaster Prevention Research Institute, Kyoto University, \\ Kyoto, Japan \\ (Received July 21, 1975; Revised January 10, 1976)
}

\begin{abstract}
The regionality of the crustal structure under Japan was examined from the analysis of surface waves, which were observed by long-period seismographs at Amagase. The analysis was carried out based on bandpass filtration. The group velocities for several paths around Japan were well determined for periods from 10 to $50 \mathrm{sec}$. The group velocities of Rayleigh waves passing through Japanese Islands could be compatible with those based on the J-S-Cl model, estimated from the refraction experiments, but on the other hand, those of Love waves gave slightly higher values than those from the J-S-Cl model. In general, the group velocities for the oceanic path were higher than those for the inland path of Japan, and moreover the values of the Japan Sea were higher than those of the Pacific Ocean. The values for paths grazing along the Pacific coast line of Japan were very low among the data examined in the present study.
\end{abstract}

\section{Introduction}

The automated-analysis system for the detection of $\mathrm{P}$ and $\mathrm{S}$ waves of the local earthquakes (S-P $<10 \mathrm{sec}$ ) was described in an earlier paper (FURUZAWA, 1974b). In order to apply the procedures of this analysis system to seismic data of events at farther distances, more information on crustal structures are indispensable to discern the various effects of later phases.

As for the crustal and upper mantle structures in Japan, the P-wave velocity models along several profiles were suggested based on explosion experiments by the Research Group for Explosion Seismology. And the shear-wave models were proposed from the analysis of surface waves of teleseismic distances (AKI, 1961; Kaminuma, 1966; Kanamori and ABe, 1968). It is indispensable to discuss the regionalities of crustal structures in such a complicated region as Japan. On the other hand, a great deal of earthquakes with magnitudes 5 to 6 have occurred near Japan and the wave trains of surface waves of these earthquakes have often been recorded by the long-period seismographs. Therefore, the analysis of these surface wave data with short paths 


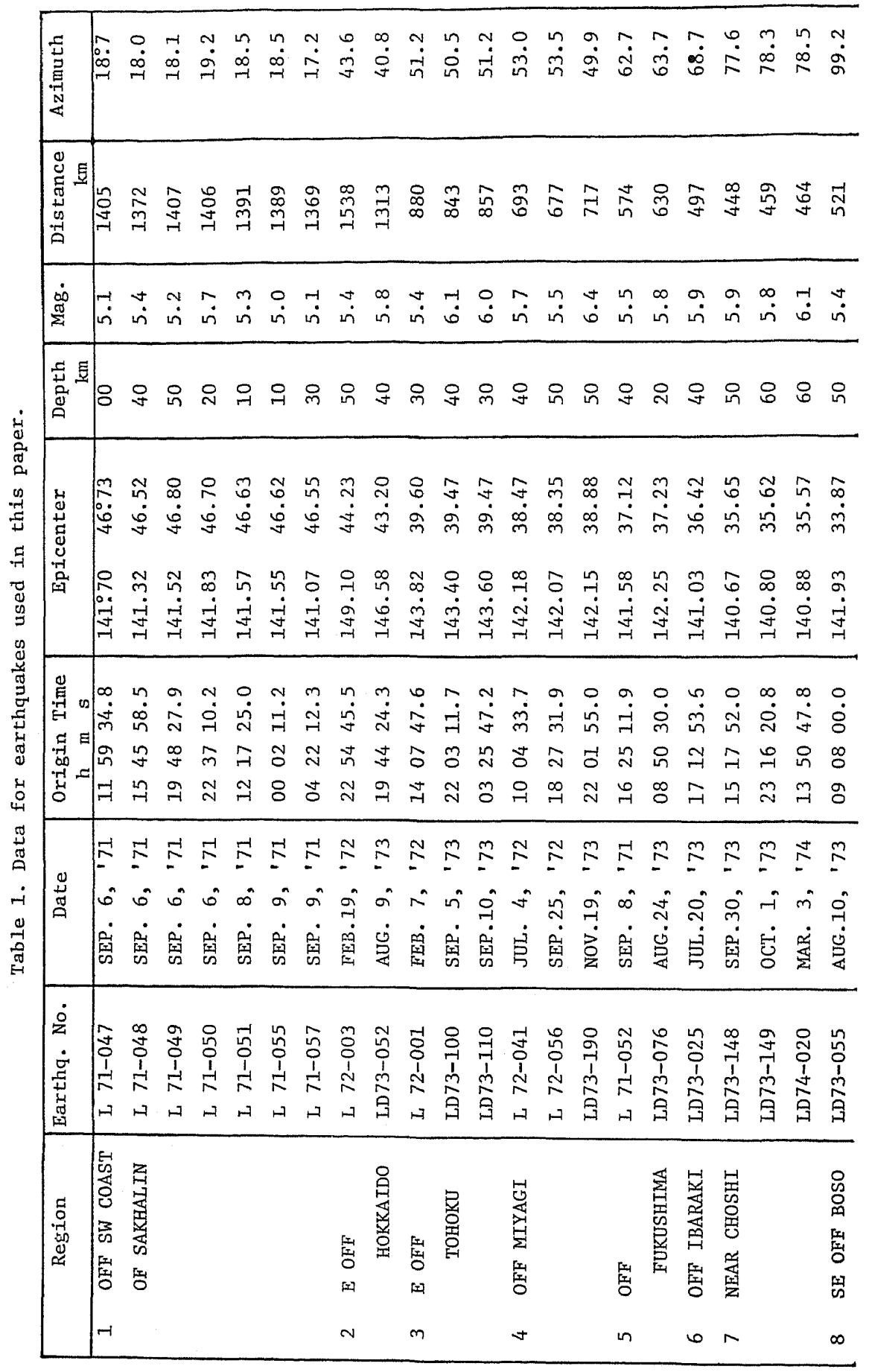




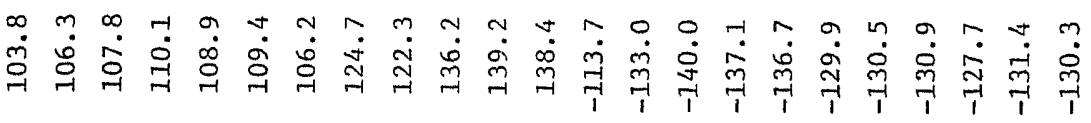

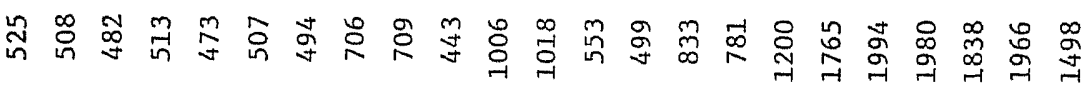

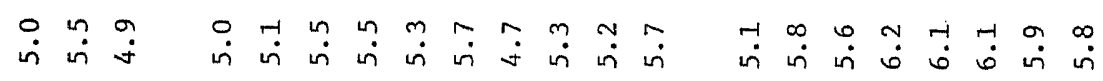

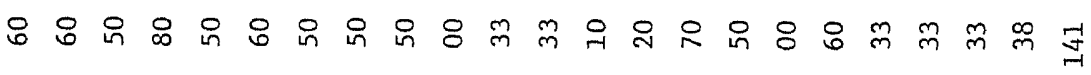

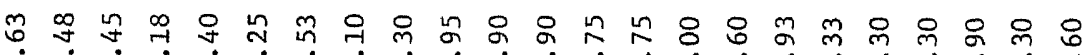

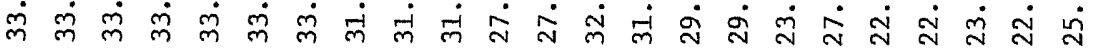
m

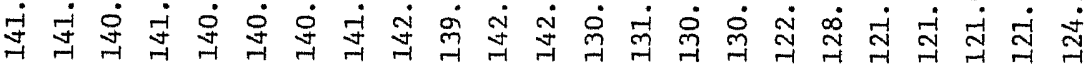

ฯ

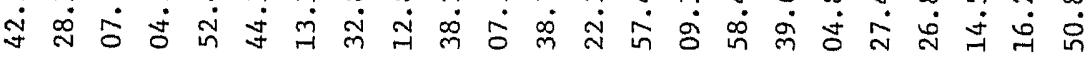

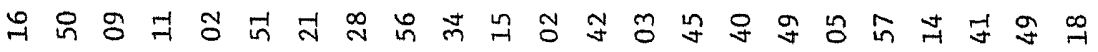

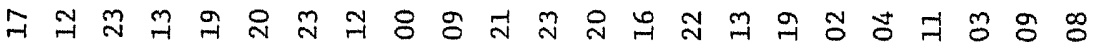

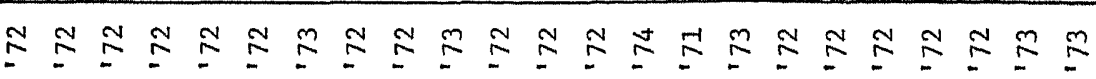

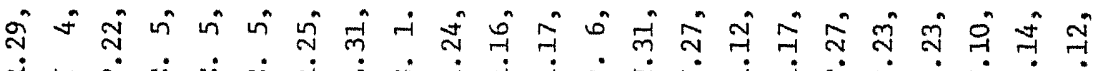

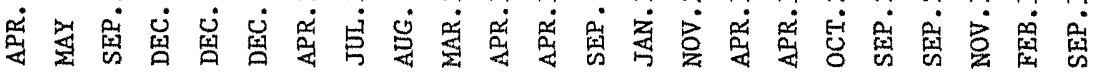

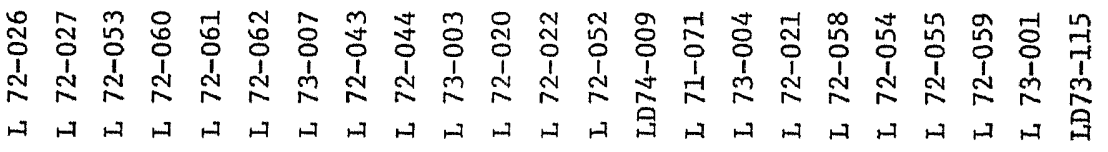

\begin{tabular}{|c|c|c|c|c|c|}
\hline 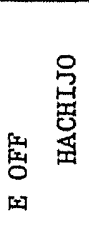 & 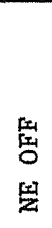 & 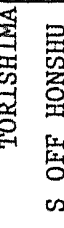 & 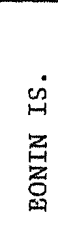 & 出葛 & 㴔莣 \\
\hline$a$ & 암 & 7 & $\mathcal{F}$ & 27 & $\stackrel{0}{0}$ \\
\hline
\end{tabular}


in various azimuths is instructive for the study of the regionality of crustal structures around Japan, particularly under the sea.

But the analyses of surface waves for short ranges are rather difficult due to the undevelopment of dispersions and contaminations by short-period waves with large amplitudes. In this paper, considering the condition as mentioned above, the bandpass filtration technique, which is recognized to be suitable to the analysis of surface waves, was applied to the long-period seismograms obtained from the direct digital recording system at Amagase station. And the group velocities of the surface waves from earthquakes at medium distances were determined for several paths around Japan. The results were also compared with some theoretical models.

\section{Data and Analysis}

The long-period seismograms recorded at Amagase station $\left(\lambda=135^{\circ} 50^{\prime}\right.$ $09^{\prime \prime} \mathrm{E}, \varphi=34^{\circ} 52^{\prime} 48^{\prime \prime} \mathrm{N}$ ) were used for the analysis of the group velocity. The
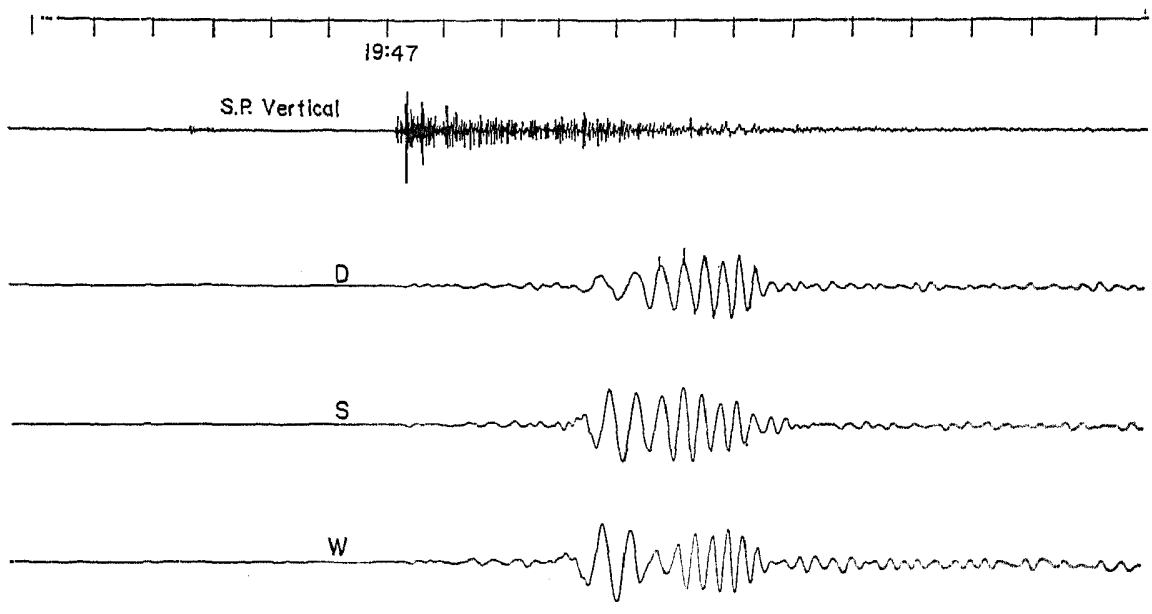

AL73-052D OFF NEMURO AUG.09, 1973

Fig. 1. Example of surface wave trains of near earthquakes from Amagase longperiod seismograms (monitoring record in digital recording system). Time marks show every one minute. Top trace represents $0.5 \mathrm{~Hz}$ low-pass filtered shortperiod vertical component. Middle three traces show three components of longperiod seismograms. D, S and $\mathrm{W}$ mean down, south and west directions of ground motions, respectively. Lowest trace shows the triggered pulses emitted when the amplitudes of seismic waves exceed an assigned level. 


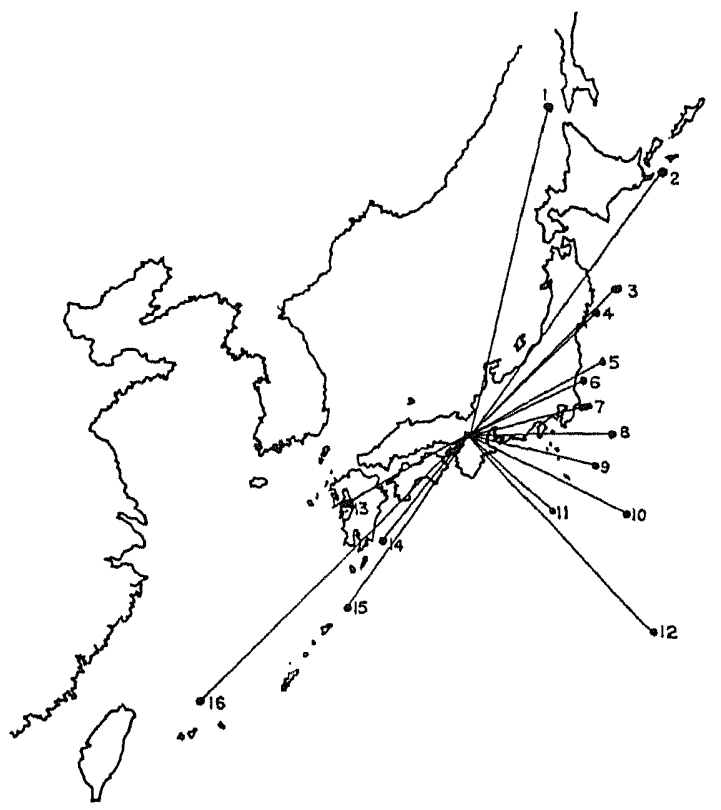

Fig. 2. Map showing epicenters and propagation paths to Amagase. Numbers refer to the regions listed in Table 1.

earthquakes with magnitudes 5.0 to 6.5 occurred near Japan from 1971 to March of 1974 were used for the present analysis and are listed in Table 1 arranged in the order of the path azimuth from the station. The data on hypocenters were taken from the Seismological Bulletin of JMA. The epicentral distances and azimuths at the station were computed by Rudoe's formula. An example of the records is shown in Fig. 1, and the epicenters of the earthquakes and the paths to Amagase in Fig. 2. The numbers in Fig. 2 correspond to those in Table 1. The recording system at Amagase was changed from visual photographic paper recording with long-period galvanometers $(T=100$ sec, $h=1.0$ ) to direct digital recording in June, 1973 (FURUZAWA, 1974a). The seismometer pendulum is a 3-component set of long-period Press-Ewing type pendulums with critical damping constants. The free period is set to be 20 seconds. In the case of direct digital recording, the output signal from each moving coil is fed to an amplifier system with DC-amplifier and active lowpass filter networks with a corner at $0.02 \mathrm{~Hz}$ and with an attenuation rate of $12 \mathrm{db} /$ oct. The output is converted to a digital form by a five place digital voltmeter. The sampling rate is 1 per second. The data in the digital form is printed out with a digital printer operated only when the amplitude of seismic waves exceeds an assigned level. Therefore, for earthquakes before May, 1973, the group velocities were determined by the traditional "peak and trough" method from visual paper records, and from June, 1973, were deter- 
mined by the bandpass filtration method by DzIEwONSKy et al. (1969) from digital records.

To evaluate the group velocity, the effects of the source shift and instrumental response must be considered. For the periods and magnitudes of earthquakes used in the present analysis, it may be appropriate to consider that the source corrections required are small. Then only the instrumental response was considered and given as the response due to the impulse displacement, $H_{S}(f)$, which was computed by multiplying the Fourier-spectrum of the response to a step force by a factor $(i w)^{3}$. For the instrumental correction, a digital filter defined as the ratio of the transmission window, $T(f) / H_{s}(f)$, was applied to seismic data (BoGERT, 1962). The transmission window, $T(f)$, was chosen to reduce the effect of short-period microseismic noise and long-period drift;

$$
T(f)=\left\{\begin{array}{lr}
64 f, & f<0.016 \\
1, & 0.016<f<0.12 \\
\exp \left[-160(f-0.12)^{2}\right], & f>0.12 .
\end{array}\right.
$$

The records of the step response, the Fourier-amplitude response due to the impulse displacement, $\left|H_{S}(f)\right|$, and the digital filter, $H_{F}(f)$, are shown in Fig. 3. After the instrumental correction was done, the N-S and E-W components of digital records were vectorially converted to the transverse and radial components to the path.

The data equivalent to the duration of $512 \mathrm{sec}$ from the initial point of digital seismograms, digitized at $1 \mathrm{sec}$ interval, were used for Fourier analysis. A seismogram of this length includes the surface wave train near the center. For the bandpass filtration technique, the filtering function should have a good resolution in the immediate vicinity of each center frequency. In the present study, each bandpass filtration was performed in its frequency domain through the Gaussian function, $H\left(w, w_{n}\right)=\exp \left[-\alpha\left[\left(w-w_{n}\right) / w_{n}\right]^{2}\right]$, where $w_{n}$ denotes the center frequency for each band, and the parameter, $\alpha$, which controlled each filter resolution, was chosen to be 12 or 48 for comparison. The envelope functions of filtered traces were evaluated and the time referred to the maximum height of the envelope was taken as the group arrival time for each band. In the case of $\alpha=48$, the center frequencies of each filter band correspond to the frequencies referred to the group arrival time. In the case of $\alpha=12$, the period referring to the envelope maximum must be reexamined on the bandpass filtered traces, since the band width of the filter became too broad to take the center frequency for the frequency referred to the group arrival time. No appreciable differences were found between these two cases. Examples of bandpass filtered traces are shown in Fig. 4. The arrows in Fig. 4 show the positions of the maxima of the envelopes. The distinctive 

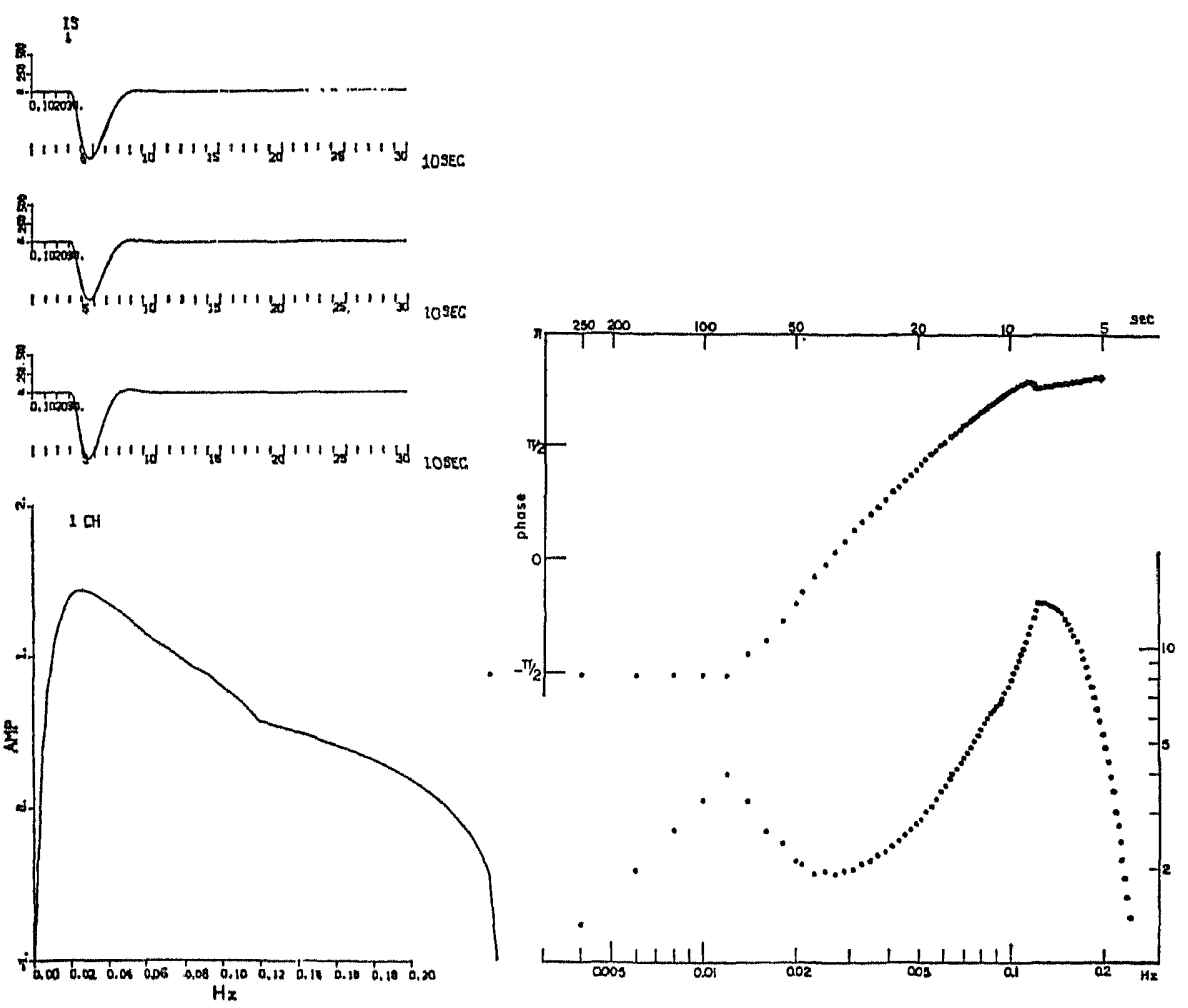

Fig. 3. Left: step responses of three components (upper three traces) and amplitude response of vertical component (lower) of the Amagase long-period seismograph. Right: the filter frequency response for vertical component for instrumental correction. upper; phase, lower; amplitude.

dispersions of Rayleigh and Love waves are recognized in the period ranges of 10 to $35 \mathrm{sec}$. The mark, $S$, shows the position of $S$ arrival obtained from the polarization of particle motions of unfiltered traces. Moreover, as seen in the highpass-filtered trace with a cut-off-period of $10 \mathrm{sec}$ in Fig. 4, the first higher modes of Rayleigh and Love waves may be recognized and is denoted by the dots, but the detailed discussion will be carried out in the future.

\section{Group Velocity}

Figures 5 to 8 show the group velocities of Rayleigh and Love waves for each path designated by path numbers 1 to 16 of Fig. 1 . The circle and cross marks show the results obtained from the bandpass filtration method and the triangle marks show those obtained from the peak and trough method. In Fig. 5, a major portion of the Sakhalin path (path No. 1) covers the Japan Sea along the west coast of the Japanese Islands, and an azimuthal angle of 


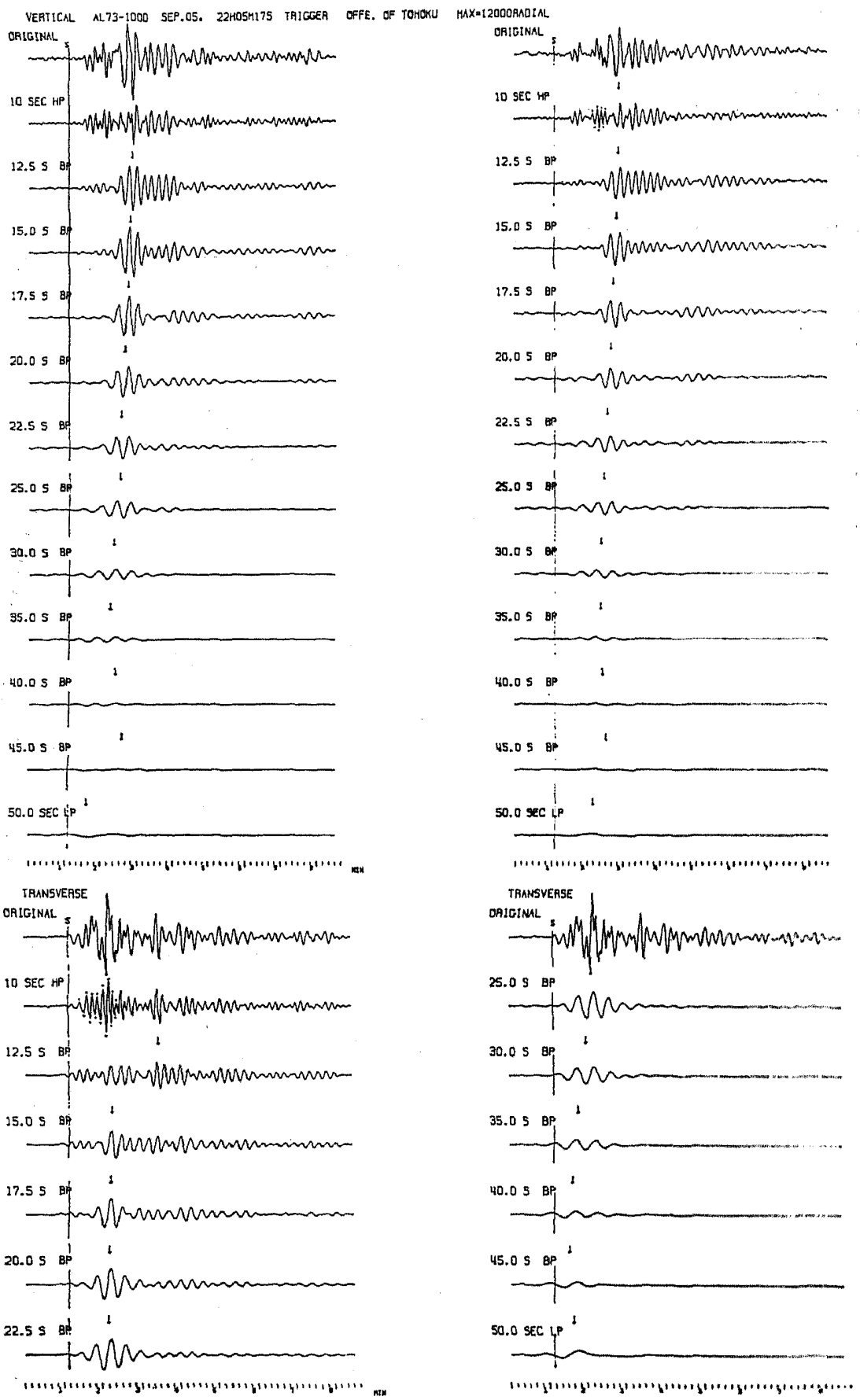

Fig. 4. Example of bandpass filtered traces. Mark, S, shows the position of S arrival. Arrows show the positions of the maxima of envelopes. 

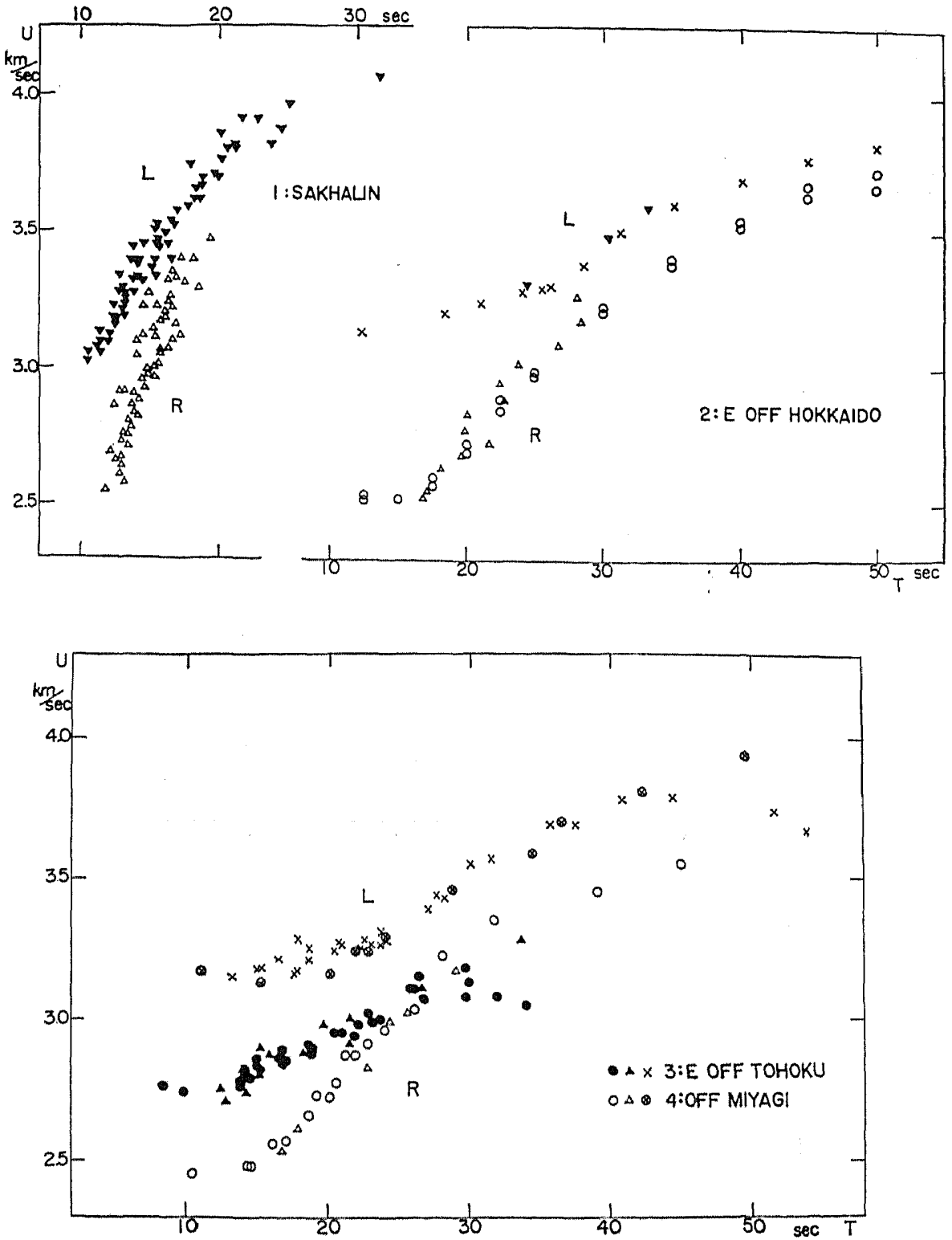

Fig. 5. The group velocity dispersion diagrams of Rayleigh and Love waves for paths of Nos. 1 to 4. R: Rayleigh wave data, L: Love wave data. The circle and cross marks show the results obtained from the bandpass filtration method and the triangle marks show those obtained from the peak and trough method. 
this path at Amagase is about $\mathrm{N} 18^{\circ} \mathrm{E}$. Though these data were obtained by the peak and trough method from visual paper records, the dispersions of Love waves were well recognized in the period ranges from 10 to $30 \mathrm{sec}$. The group velocities of Rayleigh waves were between 2.5 and $3.5 \mathrm{~km} / \mathrm{sec}$ corresponding to the period ranges from 10 to $20 \mathrm{sec}$ with slight discrepancies among indivisual earthquakes.
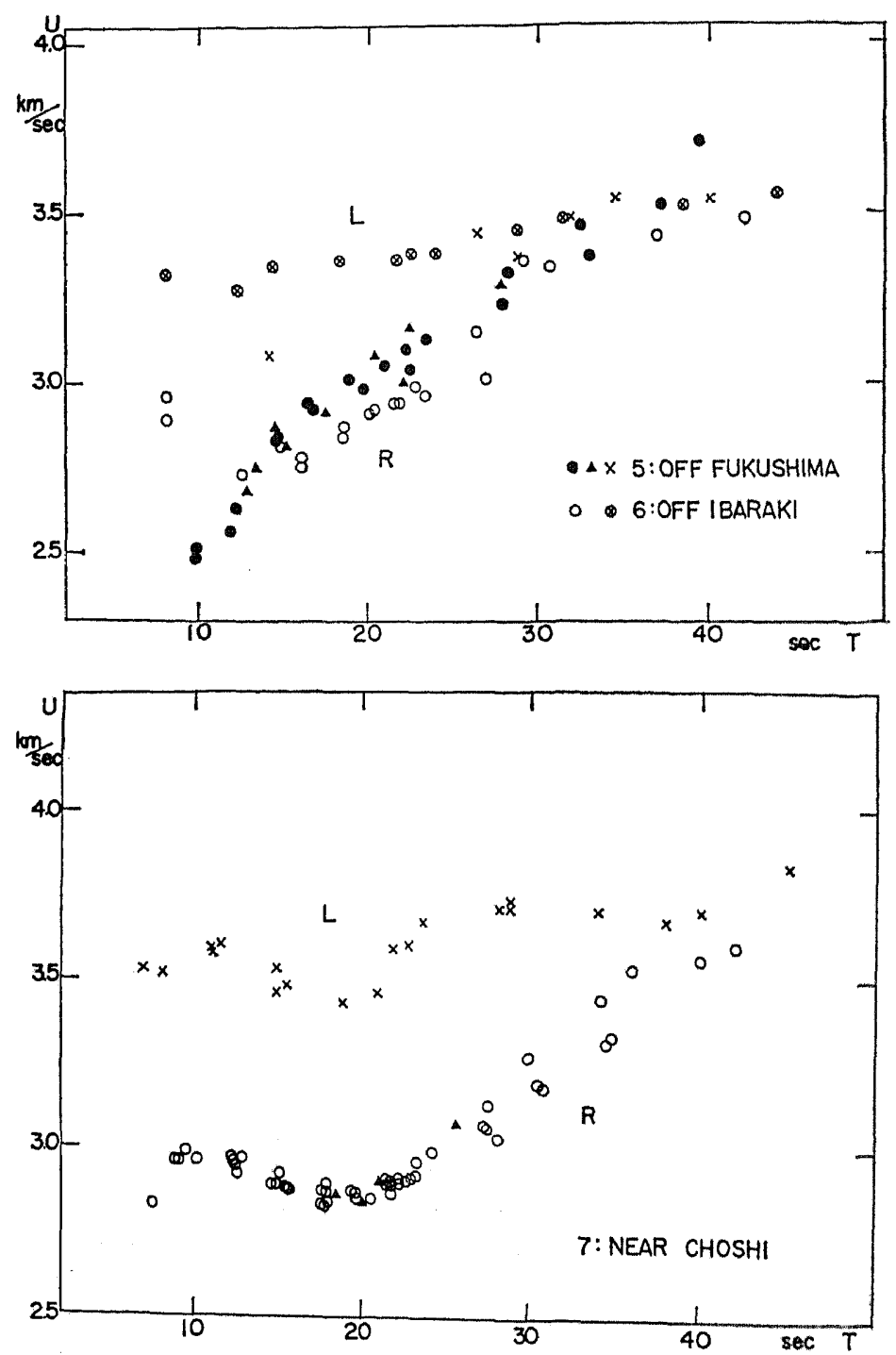

Fig. 6. The group velocity dispersion diagrams of Rayleigh and Love waves for paths of Nos. 5 to 7. R: Rayleigh wave data, L: Love wave data. Symbols mean the same as those in Fig. 5. 
The paths of numbers 2 to 4 cross the north-eastern and central parts of Honshu. For the path of No. 2 in Fig. 5, the results obtained from the bandpass filtration method and those obtained from the peak and trough method were in good agreement with each other, except that from the former method the good dispersion curves were evaluated to longer period ranges (up to about $50 \mathrm{sec}$ ) than from the latter method.

The group velocities for the path with epicentral distances from 450 to $600 \mathrm{~km}$, traversing the southern parts of the central Japan, are shown in Fig. 6. In the lower figure, the results obtained from three earthquakes near Choshi (path No. 7) gave almost the identical dispersion curves; a good agreement among group velocities was found for the same path. Thus this fact enables us to consider that the reliable group velocities in the period ranges from 10 to $50 \mathrm{sec}$ could be determined by the analysis of digital records, in spite of difficulties in dealing with those earthquakes with short epicentral distances.

Figure 7 shows the results for the paths lying predominantly across the Pacific Ocean. Love wave data were not many due to the Rayleigh wave contaminations which could not be eliminated by the visual method. The group velocities of the Rayleigh waves from the event which occurred off the Boso peninsula were considerably lower than those from the other paths.

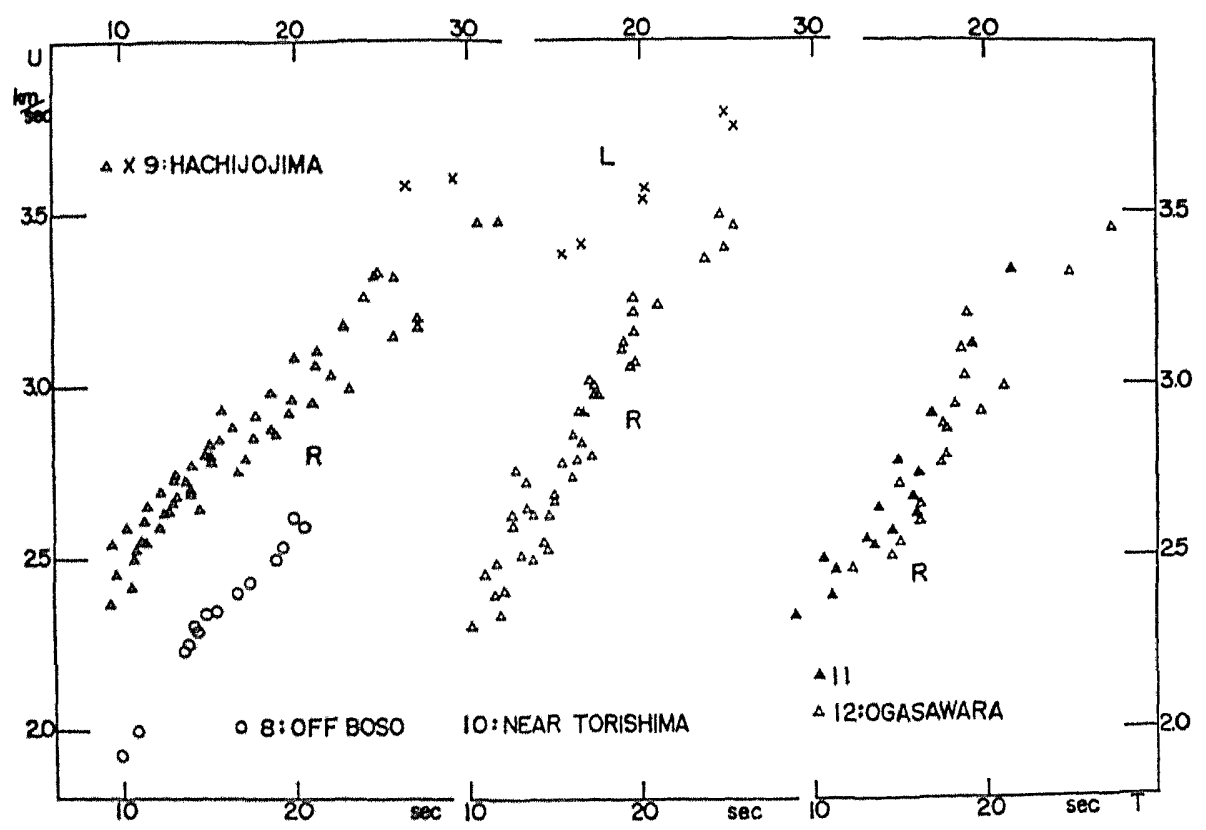

Fig. 7. The group velocity dispersion diagrams of Rayleigh and Love waves for paths of Nos. 8 to 12 . Symbols mean the same as those in Fig. 5. 

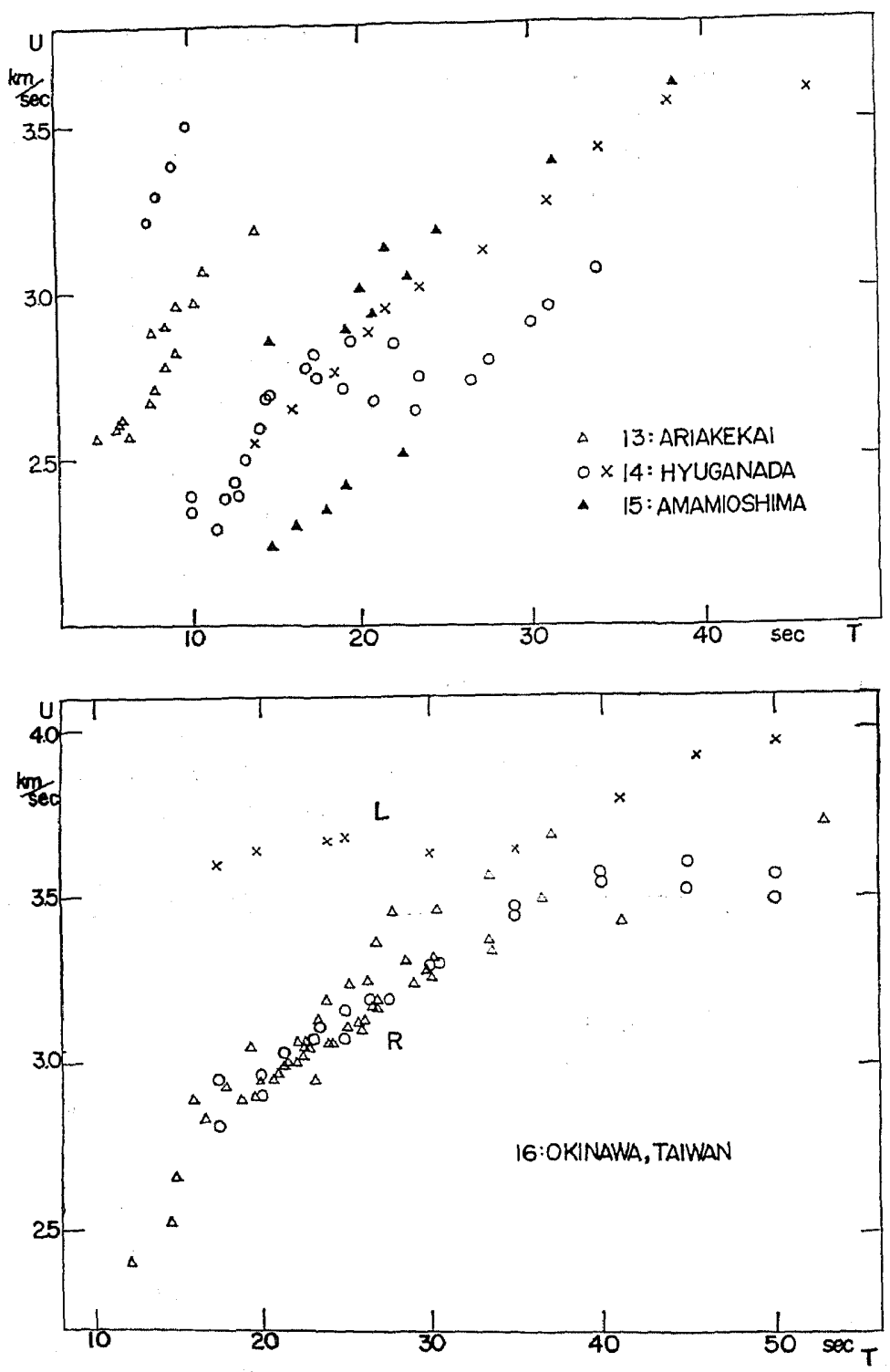

Fig. 8. The group velocity dispersion diagrams of Rayleigh and Love waves for paths of Nos. 13 to 16 . The circle, cross and triangle marks indicate the same as those in Fig. 5, respectively. Cross marks show the Love wave data. In the upper figure, open circles in the upper-left portion for Hyuganada path show the higher mode Rayleigh wave data. 
In Fig. 8, the group velocities for paths through the south-western Japan are shown. Though the paths designated by path Nos. 14, 15 and 16 have similar azimuths of about $\mathrm{N} 130^{\circ} \mathrm{W}$ at Amagase, the dispersion curves differ slightly from each other. That is, for the Hyuganada (path No. 14) and Amamioshima (path No. 15) paths, the dispersion data of Rayleigh waves were divided into two branches, as shown in Fig. 8. For the Hyuganada path the branch with lower velocities was observed at periods over $20 \mathrm{sec}$, but for the Amamioshima path at periods below $20 \mathrm{sec}$. For both paths the portions with higher velocities on the dispersions agreed with the group velocities for the Taiwan path (No. 16). For the Hyuganada path Love waves had also low velocities in the period ranges from 10 to $50 \mathrm{sec}$. For the path No. 13, passing western Japan from Ariakekai, the very high values of group velocities of Rayleigh waves were found at short period ranges from 5 to $15 \mathrm{sec}$. On the left side in the upper figure of Fig. 8 the data of path No. 13 are shown in comparison with the group velocities of the higher mode of Rayleigh waves for the Hyuganada path.

To examine the accuracy of data from earthquakes at short distances, the error in the focal parameters has to be considered. For the earthquakes used here, however, the travel times of short-period $\mathrm{P}$ phases agreed with the travel time table of JMA within $\pm 1 \mathrm{sec}$, and thus the error may be considered to affect slightly the group velocities.

\section{Comparison with Some Theoretical Models}

The averaged group velocities of Rayleigh and Love waves for each path are shown in Figs. 9 and 10, with the theoretical dispersion curves for three models. The ARC-1 model was presented by KANAMORI and ABE (1968) as the best fit model for the oceanic path around Japan. The JMA model was given by ICHIKAWA and MochIzUKI (1971) for the travel-time table for local earthquakes around Japan on the basis of the crustal structures obtained by the R.G.E.S. The J-S-Cl model derived by Kaminuma (1966) as the model fitting the phase velocity data for the central Japan had the surface layer of $1 \mathrm{~km}$ thickness over the structure given by the R.G.E.S. In Fig. 9(b), the shear velocity structures of these three models are shown.

Figure 9(a) shows the data of Rayleigh waves for paths through northeastern and central Japan. In periods beyond $20 \mathrm{sec}$ the observed group velocities of each path exhibit only slight discrepancy except for path No. 5, and generally agree with those given from the $\mathrm{J}_{-} \mathrm{S}-\mathrm{Cl}$ model within \pm 0.1 $\mathrm{km} / \mathrm{sec}$. For the periods shorter than $20 \mathrm{sec}$, there are significant differences for each path. The difference is as much as $0.5 \mathrm{~km} / \mathrm{sec}$ at a period near $10 \mathrm{sec}$ between the path No. 7 with the highest velocities and the path No. 4 with 

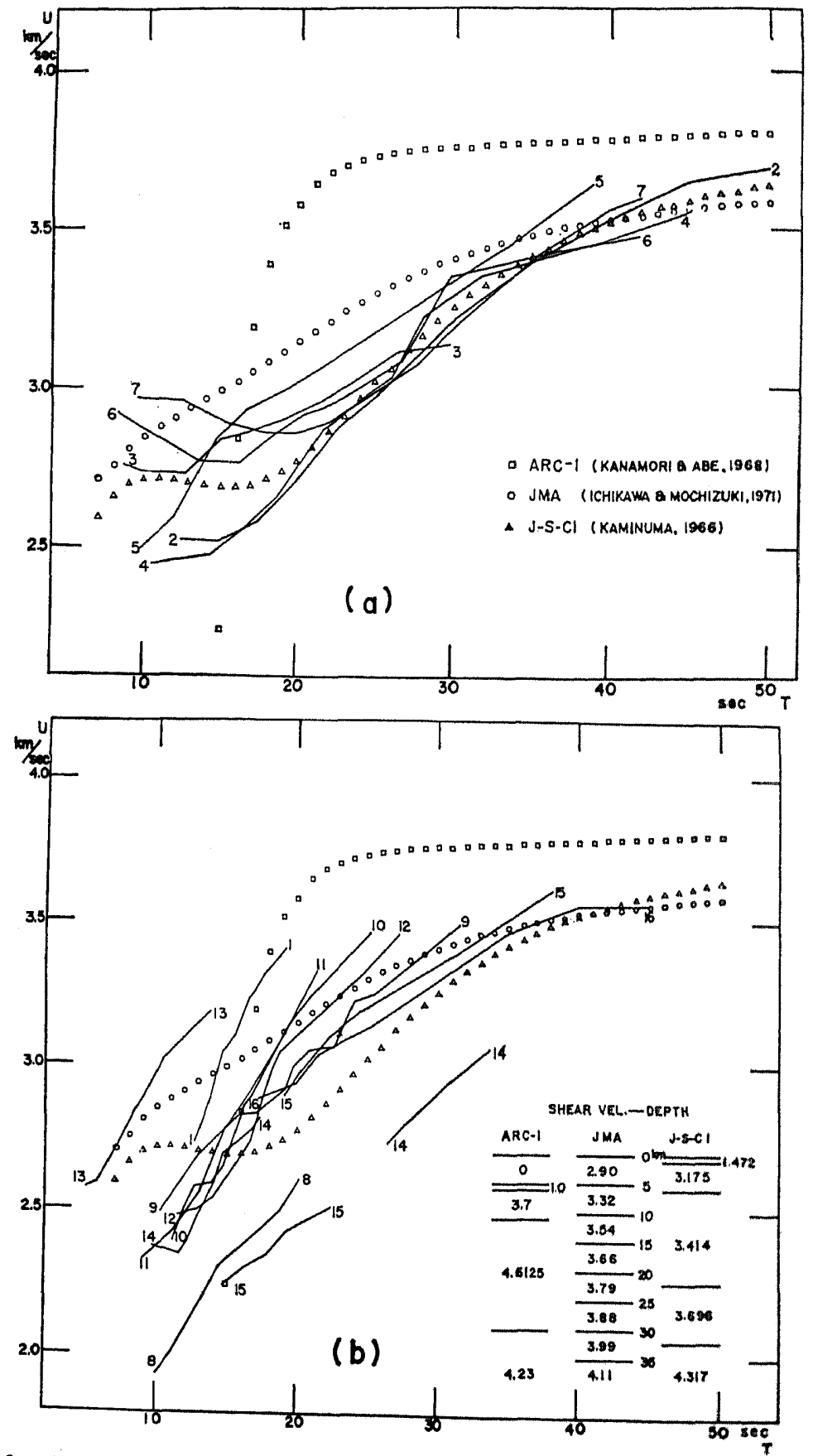

Fig. 9. Averaged observational group velocities of Rayleigh waves and three theoretical curves. (a): for paths through north-eastern Japan, (b): for paths lying predominantly under sea. 


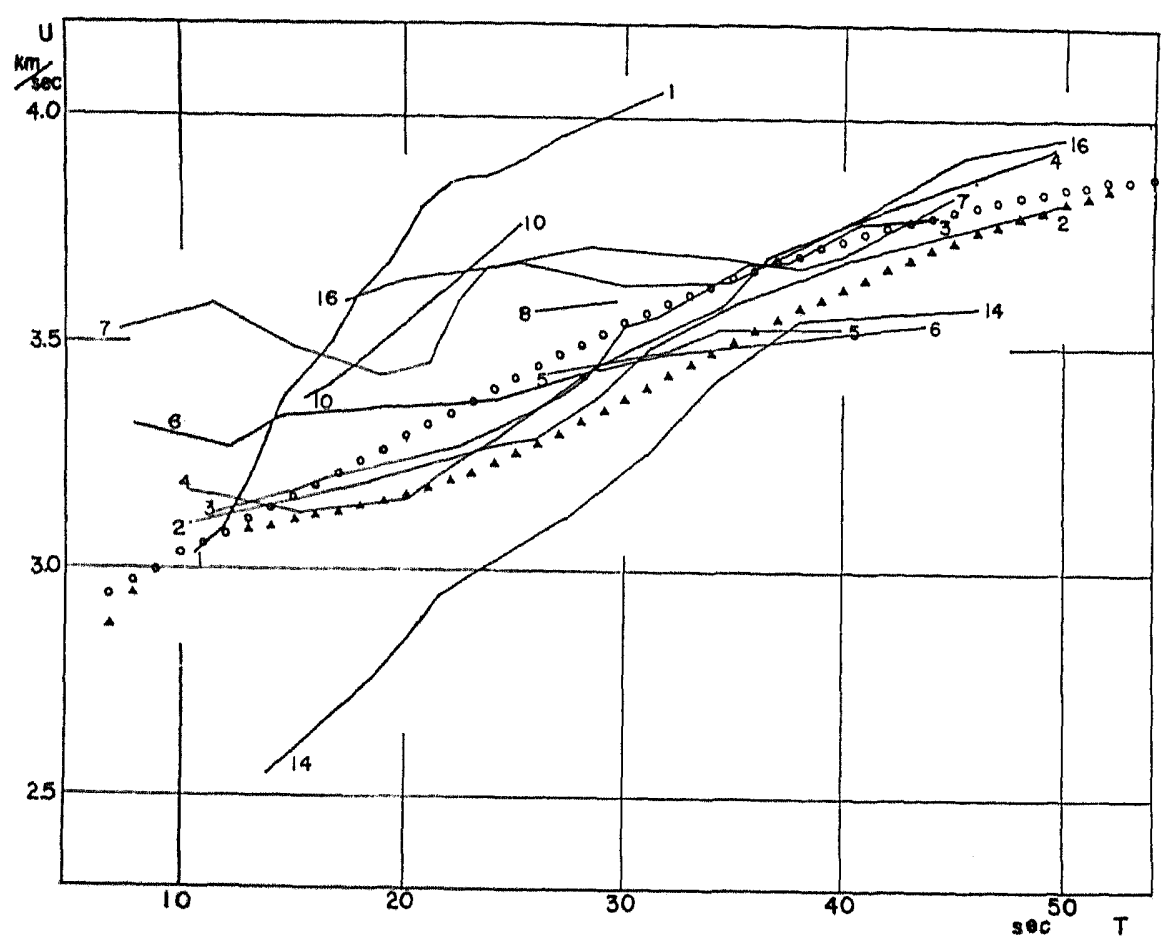

Fig. 10. Averaged observational group velocities of Love waves for all paths and two theoretical curves.

the lowest velocities. These differences are caused by both the complicated crustal structures of central Japan and the contamination of the seismograms by higher modes. The group velocities for path No. 5 are higher by 0.15 $\mathrm{km} / \mathrm{sec}$ than those for the J-S-Cl model. This discrepancy is to be examined in future study. Figure 9(b) shows the Rayleigh wave data for paths which lie predominantly under the sea. The velocities in period ranges beyond 20 sec for the path from Taiwan, Ryukyu and Nansei Island to the southern coast of Kyushu and Shikoku are higher by 0.1 to $0.15 \mathrm{~km} / \mathrm{sec}$ than those for northeastern Japan, and lie between the values obtained from the J-S-Cl and JMA models. The group velocities for paths, lying on the continental side of the volcanic ridge and trench in the Pacific Ocean, are higher than those obtained from the JMA model, but are not so high as those for the ARC-1 model. In periods below $20 \mathrm{sec}$, the group velocities for all paths generally agree with each other, and become lower than the values obtained from the JMA and $\mathrm{J}$-S-Cl models, and decrease rapidly as the period decreases. This is probably due to effects of the surface water layer. The group velocities for the Japan Sea path are highest at periods near $20 \mathrm{sec}(3.4 \mathrm{~km} / \mathrm{sec})$ and approach those of the ARC-1 model. The paths which graze along the coast line of Japan 
from Hyuganada, Amamioshima and Off Boso region have exhibited the lowest group velocities which are lower by 0.3 to $0.35 \mathrm{~km} / \mathrm{sec}$ than those of the J-S-Cl model.

A summary of Love wave group velocities is shown in Fig. 10. For paths through north-eastern and central Japan, the observed data are consistent with each other but have higher velocities by $0.1 \mathrm{~km} / \mathrm{sec}$ than those for the J-S-Cl model. In the period ranges of 30 to $40 \mathrm{sec}$, they agree well with the JMA model. For paths under the sea the group velocities are much higher than those for the JMA model, but lower than those for the ARC-1 model. The data for the ARC-1 model with about $4.3 \mathrm{~km} / \mathrm{sec}$ at periods beyond $20 \mathrm{sec}$ are out of scale in Fig. 10. The low values of velocities for the Hyuganada path can be also observed in the case of Love waves as well as Rayleigh waves. The high velocities for the Taiwan and Choshi paths may be considered to be unreasonable, since those must be thought to be contaminated by higher-mode interference.

\section{Conclusion}

Digital records from long-period seismographs at Amagase station were examined for Rayleigh and Love waves from near earthquakes having occurred around Japan, and the group velocities for several paths could be determined well in the period ranges of 10 to $50 \mathrm{sec}$ by the bandpass filtration method. The results from Rayleigh waves for paths traversed the Japanese Island could be explained by the J-S-Cl model having the low velocity surface layer of $1 \mathrm{~km}$ thickness. The observed Love wave data for these paths were slightly higher than those expected from the J-S-Cl model. For the oceanic paths the group velocities were higher than those for both the JMA and J-S-Cl models based on the refraction studies. Surface waves crossing the Japan Sea gave higher velocities in comparison with those from the Pacific paths. Rayleigh and Love waves with very low group velocities were obtained for paths along the Pacific coast line of Japan. In period ranges below $20 \mathrm{sec}$ the group velocities exhibited significant variations with the azimuthal differences and lengths of paths. The detailed examination of these velocity variations and the derivation of the consistent theoretical models will be considered in the future together with the analysis of higher mode surface waves.

The author wishes to express his sincere thanks to Dr. Tatsuhiko Wada of Kyoto University for much valuable advice and encouragement in carrying out this work, and also to Prof. Michio Takada for his encouragement. The author is indebted to Messrs. Kojiro Irikura and Junpei Akamatsu, his colleagues, for their valuable discussions and co-operation in programming for the various computations, and to Mr. Akio Hirono for his helpful assistance in the observations. 
The author is also deeply indebted to the referees of the Journal for their suggestions.

The data processing was run on a FACOM 230-25 at the Information Data Processing Center for Disaster Prevention Research of the Disaster Prevention Research Institute of Kyoto University.

\section{REFERENCES}

Akr, K., Crustal structure in Japan from the phase velocity of Rayleigh waves; Part 1, Use of the network of seismological stations operated by the Japan Meteorological Agency, Bull. Earthq. Res. Inst., Tokyo Univ., 39, 255-283, 1961.

Bogert, B. P., Correction of seismograms for the transfer function of the seismometer, Bull. Seismol. Soc. Am., 52, 781-792, 1962.

Dziewonsky, A., S. Bloch, and M. Landisman, A technique for the analysis of transient seismic signals, Bull. Seismol. Soc. Am., 59, 427-444, 1969.

Furuzawa, T., Some problems on seismic data processing; Part 1, Observational system and instrumentation, Bull. Disast. Prev. Res. Inst., Kyoto Univ., 24, 49-66, 1974a.

Furuzawa, T., Some problems on seismic data processing; Part 2, Data processing techniques for the detection and analysis of $\mathrm{P}$ and $\mathrm{S}$ waves of local earthquakes, Bull. Disast. Prev. Res. Inst., Kyoto Univ., 24, 127-145, 1974 b.

ICHikawa, M. and E. Mochizuxr, Travel time tables for local earthquakes, Pap. Meteorol. Geophys., 22, 229-290, 1971.

Kaminuma, K., The crust and upper mantle structure in Japan, Bull. Earthq. Res. Inst., Tokyo Univ., 44, 481--518, 1966.

Kanamori, H. and K. ABE, Deep structure of island ares as revealed by surface waves, Bull. Earthq. Res. Inst., Tokyo Univ., 46, 1001-1025, 1968. 